\title{
The Reorganization by Processes and its Effect on the Organizational, Physical and Cognitive Ergonomics: A Case Study
}

\author{
Marco A de Oliveira ${ }^{1 *}$, Osmar Possamai ${ }^{2}$ and Luiz VO Dalla Valentina ${ }^{3}$
}

${ }^{1}$ Department of de Engenharia de Produção e Sistemas, Universidade Federal de Santa Catarina, 88040-970 Florianópolis, SC, Brazil

${ }^{2}$ Osmar Possamai, Departamento de Engenharia de Produção e Sistemas, Universidade Federal de Santa Catarina, Brazil

${ }^{3}$ Departamento de Engenharia Mecânica, Universidade do Estado de Santa Catarina, Brazil

\begin{abstract}
This analysis deals with the reorganization by processes occurred in the area of research and development (R\&D) in a company which is a world leader in its market, and the subsequent ergonomic changes needed. Aspects relative to organizational ergonomics are dealt with, applying to the new style of work, application of resources and the structure of task distribution. Aspects relating to cognitive and physical ergonomics are shown, focusing on environmental conditions and the interaction between the professionals of the group, and modifications made to the layout, work stations, operational procedures and training carried out. The analysis is based on a historical survey of problems encountered and their causes. Solutions adopted are based on compliance with the requirements of international rules and the needs raised by the members of the teams and professionals specialists in ergonomics. Evidences of improvement in productivity associated with the improvement of the ergonomics are presented.
\end{abstract}

Keywords: Reorganization; Ergonomics; Productivity

\section{Research Highlights}

Reorganization by processes is a driver of productivity

Literature considers isolated contribution of continuous improvement and reengineering

There is a poor analysis of ergonomics contribution to productivity

There is a need to understand how reorganization affects ergonomics

Main outcome is the determination of ergonomics contribution to productivity towards reorganization by processes.

\section{Introduction}

Market globalization and attention to safety requirements of the product and work force have motivated businesses to study the phenomenon of reorganization by processes and ergonomics, in such a way as to make the organizations more competitive, guaranteeing their survival. There is no clear mention in the written work on the subject of the relationship between reorganization and ergonomics, but it is known that the first requires the second, but the reverse, at times, is not the case. The key element for the transformation of the requirements of the final product market is the organizational structure and its various related processes. Structure is understood as levels of horizontal and vertical differentiation, their coordination and controls. It becomes necessary to think of an organizational structure as a perfect alignment between its basic components, such as its people, processes (hardware and software), and services strategy [1]. This alignment, increasingly suffers the influence of the dimensions of time (delivery), quantity, quality and safety (product and people). The pressure for time and quantity should be balanced by the need for quality and safety [2]. Quality and safety are not only linked to the characteristics of the product, but also to the personnel. It is at this point that ergonomics enters as a fundamental element. It represents the principal link, the study and development of technologies, of the interfaces between the human being and systems and between all its components, people, procedures, equipment and strategy [3]. Without ergonomics all the desired access to globalised markets is put in check. There are no more frontiers in the world, everything and everyone is exposed, practically in real-time, to public opinion, to the media, and to clients. The social and environmental responsibility is a fact. In the same way it can be seen that there exists a continuous effort by the organizations and by the organisms of standardization to bring into line and work more closely, in the sense of arriving at a common number of demands for quality, safety and environment. An example of this tendency is the study conducted by Paradis [4] shown in Table 1, which compares the standards ISO 9000, the TQM (Total Quality Management), the Malcolm Baldrige award, and the OSHAS standards. What appears as common to all of them is the role (principal) of communication in the effort to fulfill the goals, principally by means of documentation and training.

Level 1 in the Table 1 describes what we do and why, level 2 is associated with what happens, level 3 describes what the employee does, while level 4 has to do with the control of the process (how we know that it was done correctly).

The objective of this work is to show the relationship that exists between the reorganization by processes in companies, and the consequent organizational changes which arise from this movement, under the prism of ergonomics. Part 2 describes the method proposed, where the variables, adopted concepts and method analysis used are described. Part 3 deals with the empirical study. An actual example of implantation is presented, and going on from that, motivations for changes needed by the reorganization of the processes and improvements under the perspective of ergonomics (physical,

*Corresponding author: Researcher, Department of de Engenharia de Produção e Sistemas, Universidade Federal de Santa Catarina, Florianópolis, SC, Brazil, E mail: mdmaviro15@gmail.com

Received February 01, 2013; Accepted May 20, 2013; Published May 25, 2013

Citation: de Oliveira MA, Possamai O, Dalla Valentina LVO (2013) The Reorganization by Processes and its Effect on the Organizational, Physical and Cognitive Ergonomics: A Case Study. Ind Eng Manage 1: 109. doi: 10.4172/21690316.1000109

Copyright: $\odot 2013$ de Oliveira MA, et al. This is an open-access article distributed under the terms of the Creative Commons Attribution License, which permits unrestricted use, distribution, and reproduction in any medium, provided the original author and source are credited. 


\begin{tabular}{|c|c|c|}
\hline Level & Quality (ISO 9000) & Safety (OSHAS) \\
\hline 1 & Quality Manual & Safety Statement \\
\hline 2 & Procedures & Safety Procedures \\
\hline 3 & Job Instruction & Safety Practices \\
\hline 4 & Management of documentation and performance \\
\hline
\end{tabular}

Table 1: Relationship between ISO 9000 and safety requirements, adapted from Paradis (1998).

cognitive, organizational) are proved. Discussions with respect to the analyses carried out are presented. Part 4 shows the conclusions and implications involved.

\section{Proposed Method}

\section{Research variables}

The variables analyzed in this study are those related to the impact of reorganization by processes on ergonomics, more precisely organizational, cognitive and physical ergonomics. The concept adopted for reorganization by processes is that which considers a radical change in the form of thinking and redesigning the business process, such as to obtain a dramatic and sustainable improvement in quality, cost, service, lead time, flexibility and innovation [5]. The productivity improvement is associated with three factors; the delivery of results increases more rapidly than the demand, the delivery is greater for a single input and the maintenance of the same delivery for a smaller demand. The definition of ergonomics employed in this work is that given by the IEA (International Ergonomics Association, 2000), which is concerned with the optimization of social-technical systems, including their organizational, political and process structure, related to the work project and its temporal organization focusing on the improvement of the well being of the human being and on the greater performance of the system as a whole. According to Dul and Neumann [6] this definition implies that ergonomics has a social (welfare) goal as much as an economic objective (total performance of the system), and considers the physical and human psychological aspects, in the search for design solutions, the technical viewpoint as much as the organizational environment.

Making a parallel with reorganization, it can be seen that both terms (reorganization and ergonomics) are intimately related to the vision of macro processes of organization. As they proceed through the organization, permeating the basic management units - BMU (sector) and intermediate management units - IMU (departmental), inherent aspects appear as interactions between human beings and mental processes as such (post and distribution of work, decision making, level of specialization, stress, training and enablement, man -machine interaction) and the relationship with projects involving human beings and systems. This vision is nothing less than the representation of the interaction of reorganization with cognitive ergonomics. When the focus is transferred to characteristics of human anatomy, anthropometry, physiology, and biomechanics in relation to physical activity, in an environment characteristic of BMU, it refers to the relationship with physical ergonomics. The more relevant inherent questions to this approach are work position, layout, handling of materials, repetitive movements, work stations project, safety and occupational health.

\section{Method}

See Figure 1, adapted from Stoner and Greenwood [7]. It represents a model of the representation of the steps in a process of reorganization. It is possible to see that the loop symbolized by the dotted lines is very similar to the analysis and problem solving method, which is a part of TQM (Total Quality Management). Changes in the macro processes require improvements in organizational ergonomics, which in turn affect cognitive and physical ergonomics. Normally improvements from the ergonomic point of view are more easily seen at the section level (basic management units - BMU) and later at departmental level or intermediate management units (IMU).

The reorganization occurs in the organization as a whole, and the entire implementation of a new process requires alterations on different fronts. While a process is being revised, continual improvements in the 'BMU' processes are carried out. This approach allows the continuity in the implementation of the changes in various levels of the organization, providing a more rapid return of results. It can be seen that the progress of reorganization is no longer isolated, and cannot be separated from the process of continuous improvement through its intrinsic similarities as to methods, in the sense of implementation from the macro processes to the internal processes of the BMU [8].

\section{Empirical Study}

\section{Characterization of the problem}

The problem to be solved is the deficiency of the laboratories of $\mathrm{R}$ $\& \mathrm{D}$ in meeting the requirements of the project in the time (delivery), quality and quantity dimensions, with consequent degeneration in the quality of service provided and with impacts on the morale of the team (low productivity). The sector assessed in this study includes 45 people, composed of 29 engineers and 16 technicians. The activities carried out refer to the experimental validation of innovative projects, envisaging the carrying out of routine activities (technology of trials mastered in the organization), together with the conception and validation of experiments for the assessment of new technologies.

The problem has become worse because the structure of the laboratories was capable of carrying out the development of improvements in products produced at headquarters. The area was made up of highly experienced specialists, so that as the demand of the projects increased, they were transferred to the project teams. In this way they were able to meet the growing demands of tasks and motivate these personnel from their career point of view. The growth in the number of tasks continues at an accelerated rate, tending to increase year by year. Today the support given by the sector is differentiated by

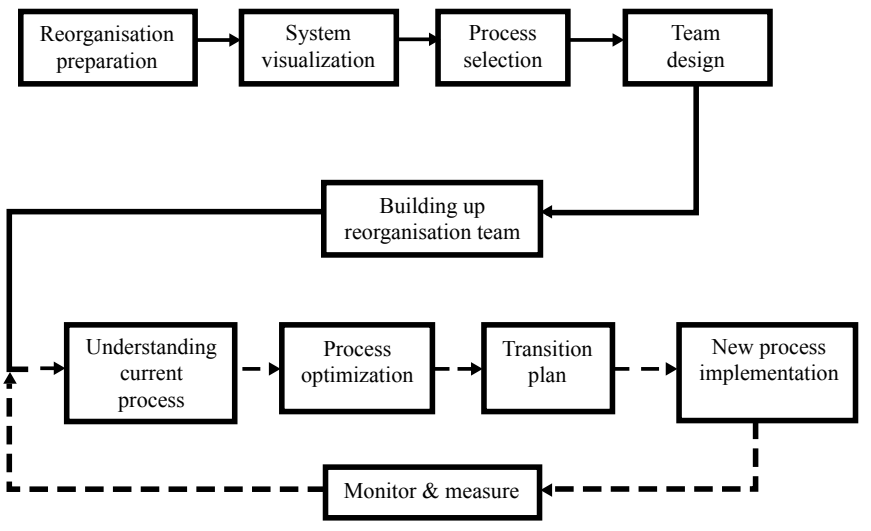

Figure 1: Model of the process of reorganization, adapted from Stoner and Greenwood (1998). 
Citation: de Oliveira MA, Possamai O, Dalla Valentina LVO (2013) The Reorganization by Processes and its Effect on the Organizational, Physical and Cognitive Ergonomics: A Case Study. Ind Eng Manage 1: 109. doi: 10.4172/2169-0316.1000109

Page 3 of 8

an increase in the range of tasks, with global scope, including technical support to other plants.

The most significant losses at present are the increase in the index of reworking caused by the inadequate training of less experienced personnel, with a consequent reduction in productivity, as well as the occurrence of several developments and analyses pending or on the waiting list provoking a delay in execution of the tasks. The existence of a degenerative routine in the processes can be noted in the hardware and software by the lack of dedication to improved procedures.

The potential gains to be realized are a reduction in reworking and the consequent increase in productivity, a greater predictability and effectiveness in the completion of tasks reflected in greater reliability in the project (product) and in an improved level of service from the sector, demonstrated by a more effective and continuous support to the clients in this area.

The goal is the establishment and implantation of a structure that enables the laboratory

- To meet the needs of the project in the areas of reliability, time (delivery), and quality.
- Provide improvement in the routines of trials, methods and equipment in a continuous manner.

- Promote the evolution and motivation of the laboratory team (morale).

- Predict and support adaptation to the peaks of job demands.

- Promote the development of know-how in measurement and analysis techniques.

- Establish a permanent network of human resource sources, via third parties, apprenticeships, exchanges (talent file).

- Create a management and training structure that backs up the needs of the laboratories and projects.

\section{Analysis of the current model}

The current working model in the laboratory, during this study is shown in Figure 2.

The most common problem with this model (Figure 3), related to personnel, is the overload of tasks that it generates and the consequent

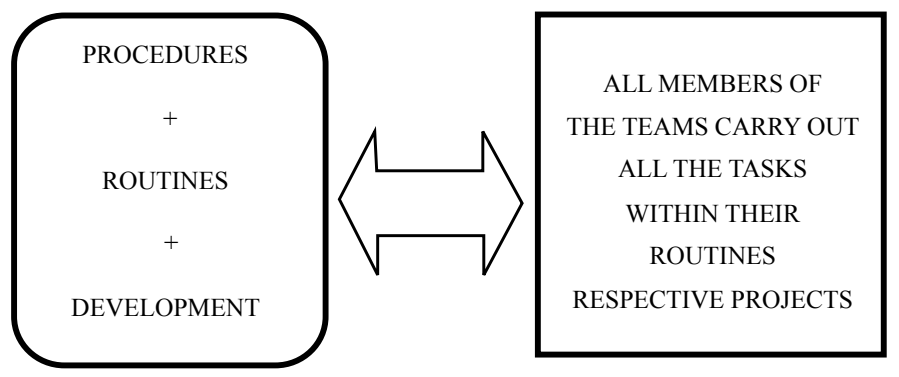

Figure 2: Representation of the laboratory working model (former).

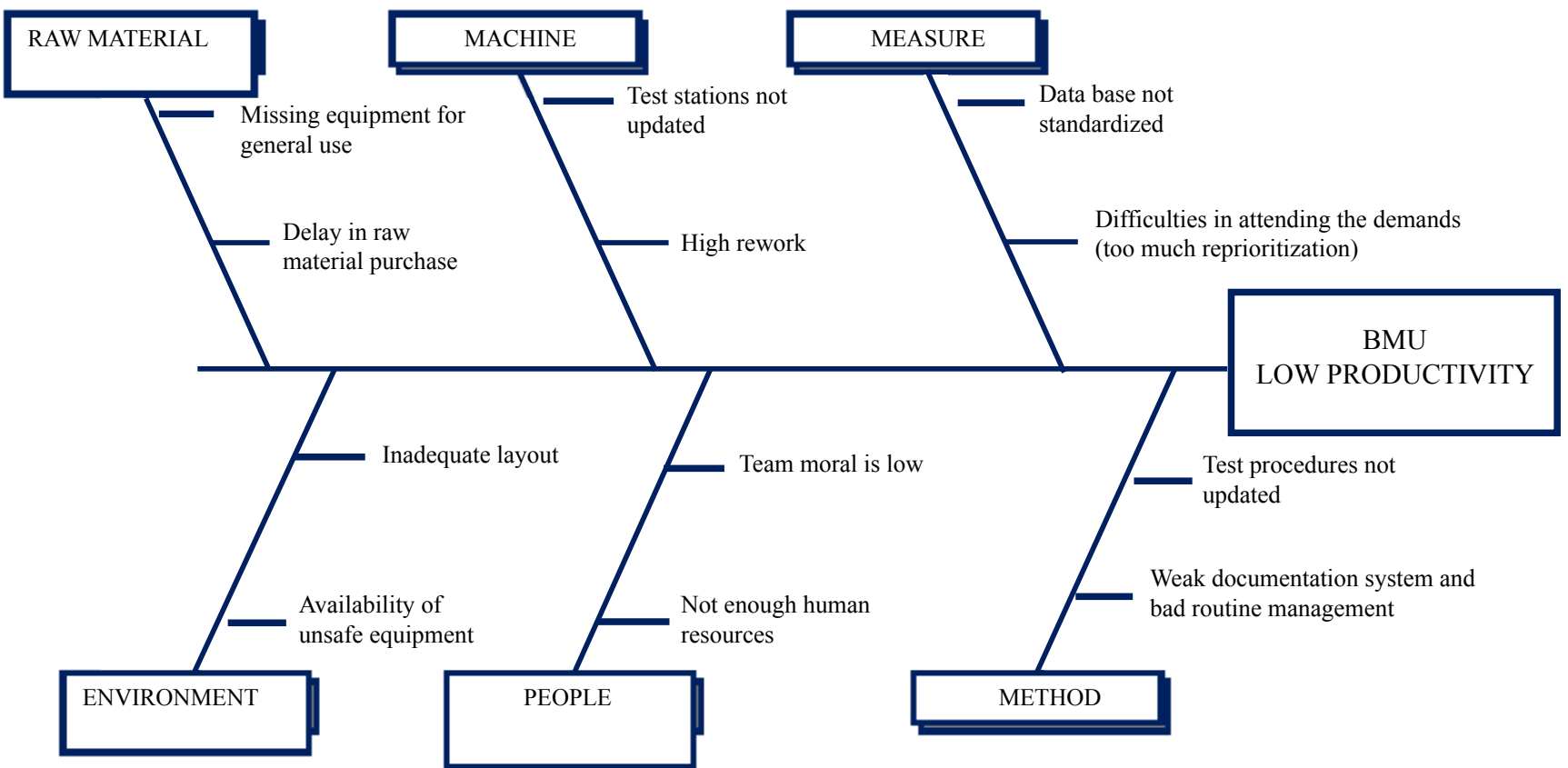

Figure 3: Diagram of the possible causes of low productivity in the analyzed area. 
Citation: de Oliveira MA, Possamai O, Dalla Valentina LVO (2013) The Reorganization by Processes and its Effect on the Organizational, Physical and Cognitive Ergonomics: A Case Study. Ind Eng Manage 1: 109. doi: 10.4172/2169-0316.1000109

Page 4 of 8

causes of loss in quality of the service provided. Another influential factor is the absence of a basic productive structure for routine tests. This happens due to the sub-location of resources for the carrying out of these tasks. In the same way an important aspect to be corrected is the lack of perfecting continuity because of the lack of time dedicated to the training of the teams. In this context the morale of the team is affected by the existence of a system to prioritize the tasks (projects) which is, at times, deficient in that the structure of the laboratory succumbs to the pressure of the clients (stress in the workforce). This generates stress in the whole team because of the high incidence of overtime and everyday pressure. As a consequence there is no time for training and little for experimental planning, and little time dedicated to self-development. New employees do not receive due attention and monitoring of the development of their skills. It appears that the strategy of personnel management is flawed. Everybody does everything, from the beginning to the end of the same routine and, in some cases, act simultaneously in two or more tasks. The layout is inadequate and envisages a high demographic density. Looking at methods and procedures (software), the main difficulty encountered is the lack of updating of the procedures, caused by the involvement of members of the team in activities of the project considered a higher priority. Tests are developed for the evaluation of projects and are transformed into a routine however many of them do not have their procedures described and standardized, causing reworking and dependence on functions and personnel. Further training and development of the team is lacking, as a form of technological updating of the laboratory. In the same way, a general vision is still lacking to better allocate human and material resources (everyone must do everything at present), which causes problems of priorities, follow up and programming of tasks. From the point of view of quality it can be seen that the experimental knowledge accumulated via development of projects and quality problems is not transformed into operational procedure. This causes a natural discontinuity in the process of the passing on of knowledge and hinders the standardization of trial routines. The data base (information) is weak and vulnerable, all in a dead file (paper), causing problems of conservation, difficult access to information and statistical treatment of data. Another point raised is the lack of the commitment of a specific resource for the analysis and implementation of improvements in assessment. There is great dependence on the tacit understanding created internally and a lack of oxygenation and openness to the entry of new technologies developed outside the organization. The perception is that there is a degenerative routine in the hardware and software now employed.

Having this information makes it possible to carry out a survey of the more probable reasons for the low productivity of the sector. The catalog of the most probable causes considers:

1. The climate in the laboratory (people)
2. The inadequate layout of the laboratory (people)

3. The lack of equipment (hardware)

4. The difficulty of sizing and prediction of laboratory resources (people)

5. The lack of improvement and updating of the experiments (hardware)

6. The lack of systematization of the routines (software)

7. The inadequate model of management and allocation of resources (software).

It is noted that a well balanced distribution exists of the causes of the problem in the personnel, hardware and software dimension. This shows that solutions should be implemented in all these areas and that the causes do not have a single origin. These actions permeate the organizational ergonomics, represented by the systematization of the routines, sizing and prediction of resources and management model of the sector as much as the cognitive ergonomics related to the improvement of methods (software), equipment (hardware) and organizational climate, and affect the physical ergonomics associated with the inadequate layout of the laboratory.

Table 2 shows the evaluation of the possibility of re-incidence of the fundamental causes raised, as well as the proposal of measures to be implemented. Short term measures are those that can be effective within a period of up to two months, whilst those of medium term need up to six months. The long term measures need more time and depend on strategic definitions (e.g. high investments).

\section{Elaboration of the plan of action}

The working out of the tasks considered most important for the solution of the problem considers the dimensions of personnel, hardware (equipment) and software (procedures and methods). The plan of action relating to personnel is shown in Table 3. The plans of action relating to the dimensions hardware and software can be seen in Tables 4 and Table 5 respectively.

So that all the improvements mentioned in the tables above should be carried out an organizational structure will be necessary which takes into account changes in the functioning of the laboratory, with a view to attending to the needs of the personnel, hardware and software dimensions [9].

\section{Proposed organizational structure}

Two organizational structures are analyzed as alternatives for the solution of the problem of low productivity of the BMU. The first of

\begin{tabular}{|c|c|c|c|}
\hline Cause & Proposed action & Guarantee against re-incidence & Implantation \\
\hline 1 & $\begin{array}{l}\text { Hold a team building training session No. Continuous } \\
\text { accompaniment }\end{array}$ & $\begin{array}{l}\text { accompaniment will be necessary to guarantee that the actions of the general plan } \\
\text { are implemented. }\end{array}$ & Medium term \\
\hline 2 & New laboratory layout & No. A master plan will be necessary for future expansion of the laboratory & Medium/long term \\
\hline 3 & Purchase of equipment and emergency instrumentation & No, however it relieves the present deficiency & Immediate \\
\hline 4 & $\begin{array}{l}\text { Define sizing strategy and prediction of laboratory } \\
\text { growth }\end{array}$ & Yes, once a way is found to bring together the sizing by specialists and projects & Rapid/medium term \\
\hline 5 & $\begin{array}{l}\text { Change to the laboratory structure. Establishment of } \\
\text { partnerships with universities }\end{array}$ & $\begin{array}{l}\text { Yes, as long as a solution is found for continuity without interruptions or redirections } \\
\text { to other tasks or projects }\end{array}$ & Medium term \\
\hline 6 & Change to the laboratory structure & $\begin{array}{l}\text { Yes, as long as a solution is found for continuity without interruptions or redirections } \\
\text { to other tasks or projects }\end{array}$ & Medium term \\
\hline 7 & $\begin{array}{l}\text { Create and implement a new laboratory management } \\
\text { model }\end{array}$ & $\begin{array}{l}\text { Yes, starting from the approach that all those involved agree to follow and maintain } \\
\text { the approach and orientations of the model }\end{array}$ & Medium term \\
\hline
\end{tabular}

Table 2: Evaluation of the fundamental causes. 
Citation: de Oliveira MA, Possamai O, Dalla Valentina LVO (2013) The Reorganization by Processes and its Effect on the Organizational, Physical and Cognitive Ergonomics: A Case Study. Ind Eng Manage 1: 109. doi: 10.4172/2169-0316.1000109

Page 5 of 8

\begin{tabular}{|l|l|l|l|}
\hline WHAT & WHY & HOW & Ergonomics Type Impacted \\
\hline New layout of the area & $\begin{array}{l}\text { Impossible expansion of experiments / bad } \\
\text { ergonomics }\end{array}$ & $\begin{array}{l}\text { Approval of the investment. Implementation } \\
\text { of the alteration. }\end{array}$ & Cognitive \\
\hline $\begin{array}{l}\text { Define strategy of laboratory } \\
\text { growth }\end{array}$ & $\begin{array}{l}\text { Improve proportion of resources of the laboratory } \\
\text { versus need of projects }\end{array}$ & $\begin{array}{l}\text { Discuss alternatives with management and } \\
\text { directors }\end{array}$ \\
\hline Training of new employees & $\begin{array}{l}\text { Accompany and direct the progress of team } \\
\text { training }\end{array}$ & $\begin{array}{l}\text { Provide internal tutors to accompany and } \\
\text { direct the team }\end{array}$ \\
\hline Team building training & Improve the team morale & Contact with HR \\
\hline $\begin{array}{l}\text { Bringing together of the } \\
\text { specialists with the laboratory }\end{array}$ & Improve accompaniment of the tasks & Promote participation of specialists \\
\hline Weekly meeting with teams & Improve accompaniment of the tasks & $\begin{array}{l}\text { Reserve 2 hours weekly for this meeting with } \\
\text { the team }\end{array}$ \\
\hline
\end{tabular}

Table 3: Plan of action in the personnel dimension.

\begin{tabular}{|l|l|l|l|}
\hline WHAT & WHY & HOW & Cognitive \\
\hline $\begin{array}{l}\text { Purchase of equipment and } \\
\text { emergency instrumentation }\end{array}$ & Relieve the present deficiency & Acquisition of the equipment \\
\hline $\begin{array}{l}\text { Change of the structure } \\
\text { (organization) of the laboratory }\end{array}$ & $\begin{array}{l}\text { Guarantee improvement of trials to } \\
\text { avoid the debasement of the routine }\end{array}$ & $\begin{array}{l}\text { Change the structure of the laboratory and establish } \\
\text { partnerships with universities }\end{array}$ \\
\hline
\end{tabular}

Table 4: Plan of action in the hardware dimension.

\begin{tabular}{|l|l|l|l|}
\hline WHAT & WHY & HOW \\
\hline $\begin{array}{l}\text { Change of the structure } \\
\text { (organization) of the laboratory }\end{array}$ & $\begin{array}{l}\text { Guarante the updating and improvement } \\
\text { of the experiments } \\
\text { and prevent a debased routine }\end{array}$ & $\begin{array}{l}\text { Change in the structure of the laboratory and establish } \\
\text { partnerships } \\
\text { with universities }\end{array}$ \\
\hline $\begin{array}{l}\text { Attend to requirements of } \\
\text { international rules }\end{array}$ & $\begin{array}{l}\text { Improvement in the safety of product and } \\
\text { environment }\end{array}$ & $\begin{array}{l}\text { Comply with requirements EN 378, ISO 14001, } \\
\text { OSHAS 18001, QC 80000 }\end{array}$ \\
\hline New data base & Reliability and information & Revise control items and new data base \\
\hline $\begin{array}{l}\text { Create and implant new } \\
\text { management model for the } \\
\text { laboratory }\end{array}$ & $\begin{array}{l}\text { To provide more agility and strength } \\
\text { in the laboratory structure }\end{array}$ & Definition of strategy for task management \\
\hline
\end{tabular}

Table 5: Plan of action in the software dimension.

them is shown in Figure 4. This presents a pyramid type structure of know-how which is based on the level of specialization required for the carrying out of routine tasks and attending to projects of research and development. Development and routine teams are also responsible for the maintenance and updating of procedures (trial methods) in their respective areas. The planning of tasks occurs in a single way that will cover all the needs of the laboratory teams.

The advantage of this structure is the improvement in the allocation of human and material resources, with the overall vision gained during the programming of tasks. This promotes a greater certainty in planning in respect of meeting deadlines and reducing reworking. In the same way maintaining a basic support structure for the laboratory routine, such as documentation and pattern trials, provides an increase in productivity and reduction in the waiting time for laboratory tasks. The greatest disadvantage of the structure in Figure 4 is the sharing of hardware (HW) and software (SW) between projects and routines that may cause problems in disputing resources and consequently impact the development time of the projects and routines. An alternative for this last situation is shown in Figure 5. The advantages of the structure shown in Figure 5 are the same ones as those found using the pyramid type structure of knowhow, however including improvements related to a reduced competition for resources between projects and routine tasks. Product projects using traditional technology, widely employed in the company make use of fixed hardware and software that is incorporated into the trial and measurement positions. Already projects of technological development (DT) are carried out on individual trial benches, where the laboratory employee has hardware and software specifically used for carrying out experiments, in the majority of cases, non-standard. This structure also envisages the maintenance of a basic support structure for the routines of expense and investment management, documentation, standardization, planning and improvement of experiments (HW \& SW).

This support structure also envisages converting a new experiment into a routine, by the confection and/or improvement in the trial stations, as well as the writing up, publishing and training of those involved in these activities. The disadvantage of the model presented in Figure 5 is the inherent cost of a mobile version of the hardware (HW) and software (SW). This structure is three times more expensive than that shown in Figure 4. This is justified by the need to adapt the work area, make improvements in the infrastructure and acquire HW and SW to carry out the DT projects. Another deficiency encountered in the management structure at the product technology level is the tendency towards the separation of the laboratory employees and their use $100 \%$ of the time in the projects. This is a point that needs special attention so as to avoid a return to a degenerative routine in the processes, and problems of physical (layout) and cognitive (interaction between people and the exchange of information and experiences, stress level) ergonomics.

\section{Results}

The increase in productivity resulting after the changes in the processes in the area evaluated are found in Figures 6 and Figure 7.

Two forms of checking were used to monitor productivity 


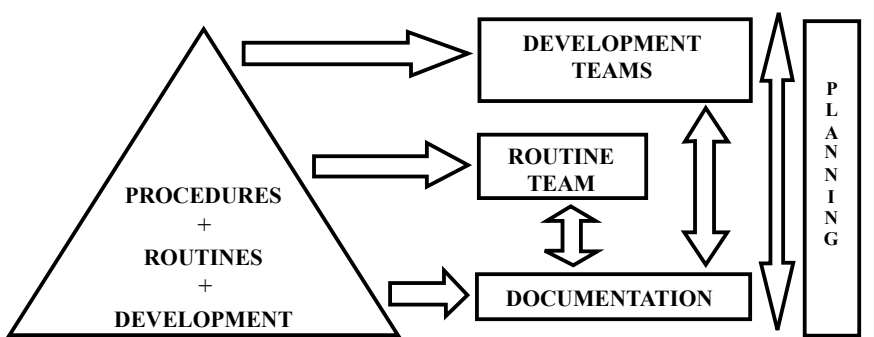

Figure 4: Proposed pyramid type structure of know-how (specialization).

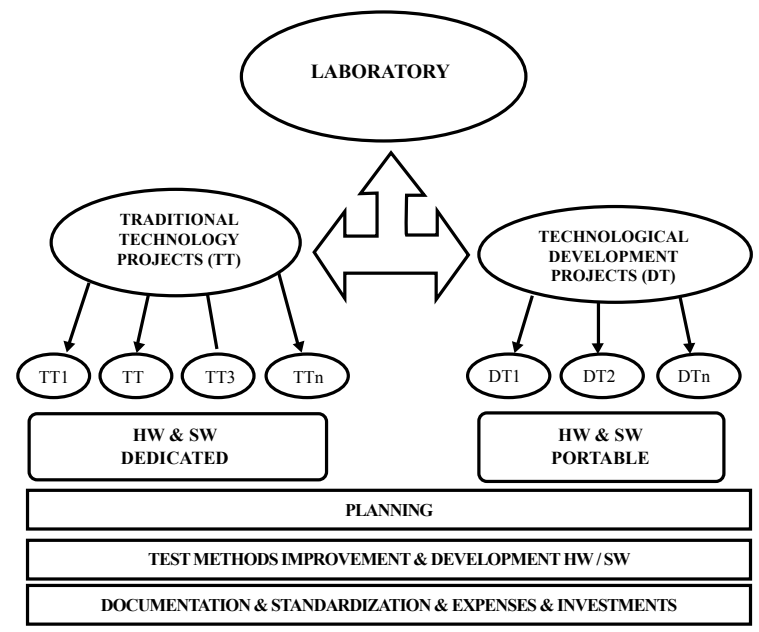

Figure 5: Proposed management structure for the product technology level.

variation. The index of effectiveness of delivery reflects the meeting of the deadlines previously agreed with the project leaders responsible for the carrying out of the required tasks. It is represented by the formula: $\mathrm{IA}=((\mathrm{QTDD}-\mathrm{QTDA}) / \mathrm{QTDD}) \times 100$

Where:

QTDD - quantity of tasks needed

QTDA - quantity of tasks completed late (delayed)

Another item used in this study was the index of repeated work (IR). The formula that describes it is:

$$
\mathrm{IR}=(\mathrm{QTDR} / \mathrm{QTDD}) \times 100
$$

Where:

QTDD - quantity of tasks needed

QTDR - quantity of tasks repeated (reworked)

The implementation of the pyramid type organizational structure of know-how (PKS) (Figure 4) took place in 2005. The reason for the choice of this model was the need to be able to predict investments for the alteration of the layout, the purchase of instrumentation and the contracting and training of personnel up to the implementation of the management structure at the product technology level. This structure lasted until 2008, during which period there was an improvement in productivity reflected in the increase of IA of $80 \%$ (old model) to close to $100 \%$ (Figure 6) in a reduction of IR $10 \%$ to $8 \%$ (Figure 7 ). In the second stage the change took place to the management structure by product technology level (PTS) (Figure 5), whose results showed a reduction of IR to 5\% in 2011. In this situation the levels of IA remained constant.

\section{Discussion}

Figure 8 shows a proposed relationship, between the reorganization, the organizational structure [1] and ergonomics. With respect to service strategy, the appearance of tasks related to organizational ergonomics is predominant, focused on the organizational, project and time management structure and quality management. Cognitive and physical ergonomics interact more strongly with the personnel and process (hardware and software) components, and promote tasks related to work station, safety, health, mental loading, profile of the operator versus the activity, stress and training profile. From the point of view of organizational ergonomics, the great modifications that contributed to improvements in the process, via the implementation of the proposed organizational structures, were the change in the project and work distribution, time management, and the strengthening of team work. This raised the concern and effective practice of community ergonomics [10-12]. As a matter of fact, the success of the whole implementation resides in this point, that is, in the participation of the teams from the beginning of the process, from the first brainstorming, in the characterization of the problems and their causes, and in the suggestion and carrying out of the improvement tasks. In this sense, it is worth emphasizing, the magnitude of the challenge considering

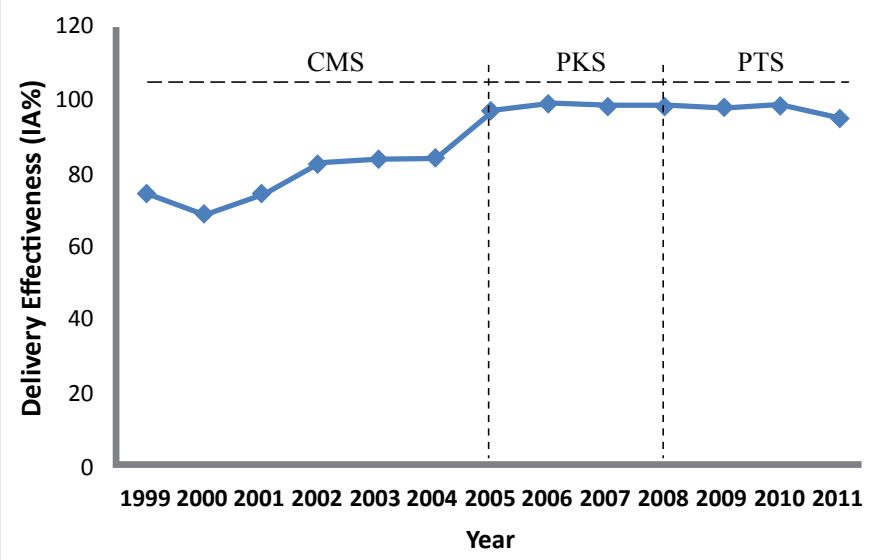

Figure 6: Evolution of the effectiveness of the activity realized over the years.

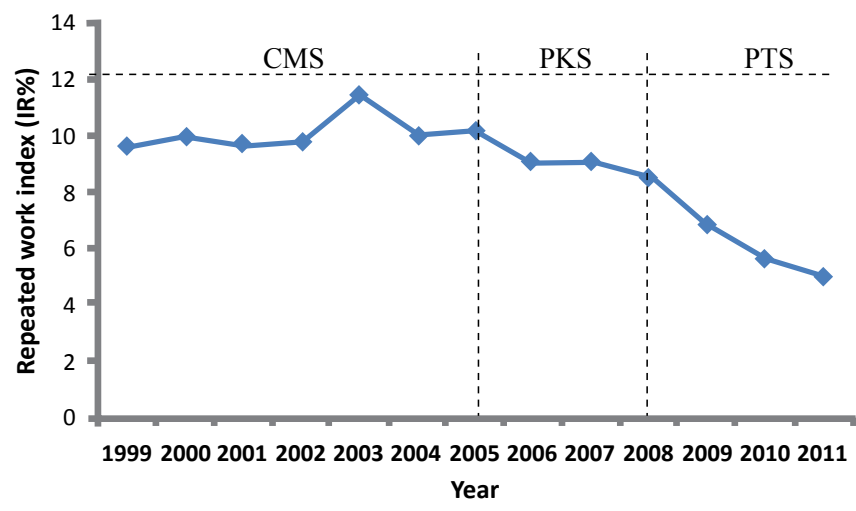

Figure 7: Evolution of the repeated work indexes over the years. 


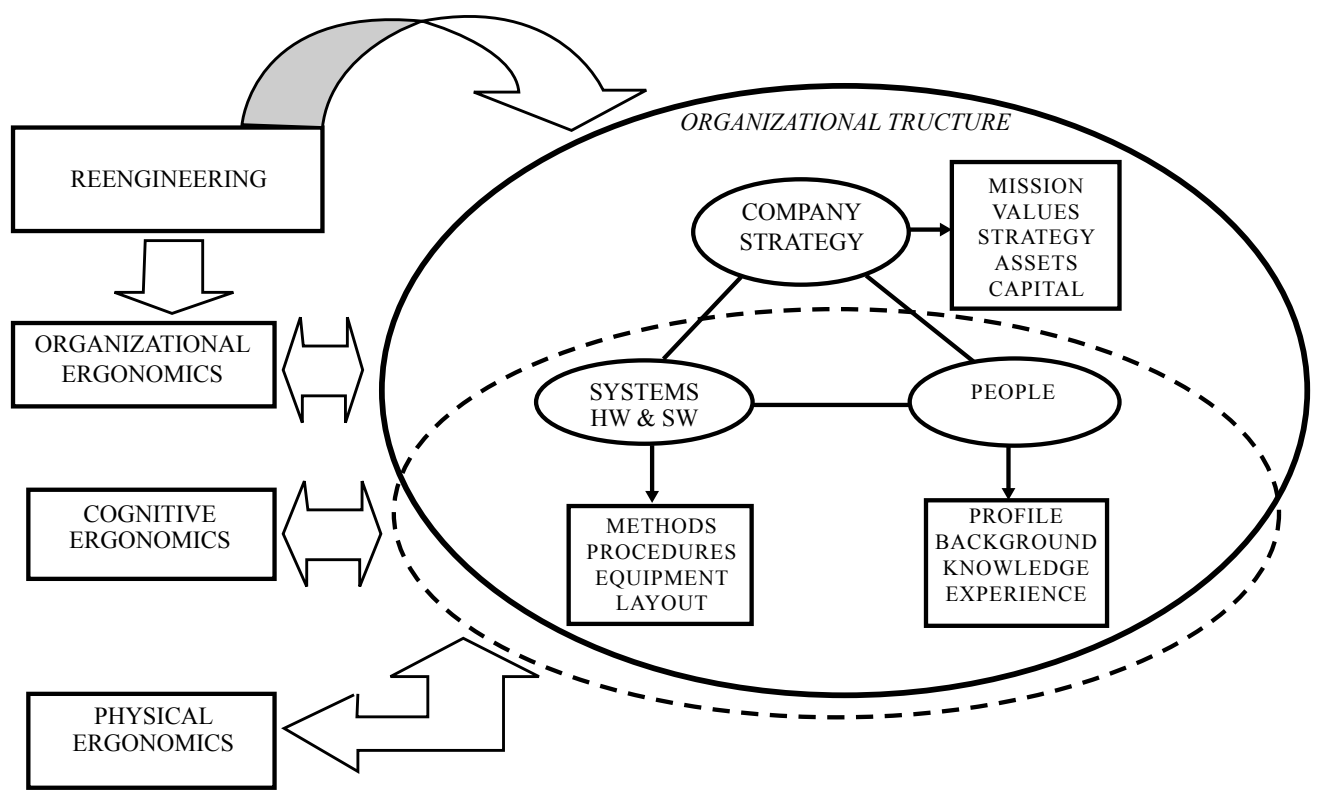

Figure 8: Proposed relationship between the reorganization, organizational structure and ergonomics.

the size of the structure, its complexity and vision for the future. A fundamental tool in carrying out the tasks was the use of TQM and of the PDCA, because of the way it disciplines and carries out the stages, without overwhelming any of them [13]. As results show, from the viewpoint of organizational ergonomics you have the extrapolation of the scope of the work, from meeting local needs to meeting globalised needs serving as motivation and the creation of opportunities for the employees of the organization, the increase in the diversity of approved products ( 3 lines of local products to 8 lines of global products), change in the profile of those in the areas involved (technical and engineering) and creation of a career plan in accord with the challenges and aspirations of the teams.

From the point of view of physical ergonomics the most significant changes were related to the adaptation of the work stations, training and enabling of the teams, via an individual and annual development plan, selection of areas and layouts for laboratories, taking into consideration their needs and requirements in accordance with international rules (ex. Series EN 378, ISO 9001, ISO 14001, OSHAS 18001, and QC $80000)$. As a result of research carried out in the sphere of the area evaluated an increase in the index of user and client satisfaction from $55 \%$ to $85 \%$ was obtained.

There was a reduction of 3 times in the safety risk factor in the area (from greater to lower). Another form of monitoring is the annual goal for the work accident rate, which is zero considered with separation and 3 without separation. In this sense the historic rate has been maintained very well, in fact better than the accident rate goal without separation $(>3)$. From the point of view of cognitive ergonomics, the great challenges were the alteration of the activity profile and the consequent change in the profile of the team members $[14,15]$. This ended up bringing about a lengthy dedication to the building of a network of contacts with technical schools and universities, in the search for potential talent. Another task developed was the adaptation of the demands of new projects with this new profile for the members of laboratory teams. This demanded the creation of a new career plan, seeking to increase the perspective of personal growth together with the technical challenges imposed. Training in team building and research into the internal climate are tools used to monitor the team satisfaction level. Another relevant aspect was the standardization achieved. The accumulated know-how of the employees was added to operational standards. The next step was education and training with the enabling of the teams in the new technologies and processes, and achieving the diagnostic of the operational work. Eventually the entire laboratory work force was certified again.

\section{Conclusion}

There is a similarity between the chronological order of the evolution of the organization and ergonomics. This is basically due, simultaneously, to the evolution of the organization of the work as time went by, as shown by Iida [16]. At first the focus was on physical ergonomics, considering only work stations and tools. Then it moved on to cognitive levels as the tasks became more complex, demanding multifunctional personnel. Later organizational ergonomics emerged, centered on the optimization of work methods, the distribution of the work load in its complexity and in the organizational structures and in the way the work is distributed. The work performed in the organization sought to improve the environment, by means of the humanization of relationships and the understanding of the causes of dissatisfaction among the workers. The most common categories of these sources are: the physical environment, the psycho-social environment, wages, the workweek, and work organization. The work content (quantity and quality, work conditions, organizational factors, (pressure from superiors, jobs and wages, work hours, motivation, overtime and shifts), and social-economic pressures (survival, lifestyle maintenance) were analyzed [17]. The enrichment of the jobs was opted for, by redesigning the work stations, training, individual and collective, for newcomers and the experienced, with a career plan designed to meet the jobs and salary expectancy, with opportunities for advancement (motivation). From the point of view of organization and work distribution, direct controls over the tasks were removed. These become more difficult and challenging, and took place in more integrated work stations, and 
Citation: de Oliveira MA, Possamai O, Dalla Valentina LVO (2013) The Reorganization by Processes and its Effect on the Organizational, Physical and Cognitive Ergonomics: A Case Study. Ind Eng Manage 1: 109. doi: 10.4172/2169-0316.1000109

with a greater degree of autonomy. Workers had greater control over results, with the employees monitoring the processes. The basis for this was the forming of multifunctional teams, enabled through training, with a higher level of specialization.

As a result it was noted that the key elements for the success of this endeavor were the strategy of approach and the method employed to implement the improvements, and principally the involvement of the employees from the beginning of the process. This makes them feel like owners, providers, and auditors of the processes related to their area of work. The great challenge, to be continuously monitored, is the level of stress arising from the conditions produced by the pressure for results. Although there are very positive aspects that tend to balance the requests and demands, it is important to note that individuals respond differently to these stimuli, and are influenced by the situation. It can be seen that questions associated with cognitive ergonomics should be monitored frequently, that is, greater attention given to questions related to the interaction between human beings and mental processes as such, like the workload, decision making, level of specialization, stress, training and enabling, and the relationship with projects that involve human beings and systems.

\section{References}

1. Albrecht K (1988) At America's Service - How Corporations Can Revolutionize the Way They Treat Their Customers. Dow Jones Irwin

2. Wilson JR (2000) Fundamentals of ergonomics in theory and practice. App Ergon 31: 557-567.

3. Hendrick HW (2000) The technology of ergonomics. Theor Iss Ergon Sci 1: 22-33.

4. Paradis J (1998) Leadership and Harmonization: Reengineering the Manager's Role in Continuous Improvement. ASQC 49th Ann Qua Cong Pro 49: 526-531.
5. Gunasekaran A, Kobu B (2002) Modeling and analysis of business process reengineering. International J Prod Res 40: 2521-2546.

6. Dul J, Neumann WP (2009) Ergonomics contributions to company strategy. App Ergon 40: 745-752.

7. Stoner DL, Greenwood P (1998) Reengineering: A Systems Approach. ASQC 49th Annual Quality Congress Proceedings.

8. Dalla, Valentina LV (1998) Desenvolvimento de um modelo integrado de reorganização de processos com melhoria contínua para redesenho de processos. Tese de Doutorado, Departamento de Engenharia de Produção e Sistemas, UFSC.

9. Paris RC, Salas E, Cannon-Bowers JA (2000) Teamwork in multi-person systems: a review and analysis. Ergon 43: 1052-1075.

10. De Jong AM, Vink $P$ (2002) Participatory ergonomics applied in installation work. App Ergon 33: 439- 448.

11. Kogi K (2006) Participatory methods effective for ergonomic workplace improvement. App Ergon 37: 547- 554.

12. Shorley L, Dennis G (2010) Participative Ergonomics as an Organizationa Manual Task Risk Management Process in QR Infrastructure Service. Safer and Productive Workplaces: Proceedings of the 46th Annual Conference on the Human Factors and Ergonomics Society of Australia 20-32.

13. Carayon P, Smith JM (2000) Work organization and ergonomics. App Ergon 31:649-662.

14. Costigan RD (1995) Adaption of traditional human resources processes for total quality environments. Qua Manag J 7-23.

15. Johansson J, Abrahamsson L (2009) The good work-A Swedish trade union vision in the shadow of lean production. App Ergon 40: 775-780.

16. lida I (1992) Ergonomia, Projeto e Produção. Edgard Blücher Editora.

17. Upton C, Doherty G, Gleson F, Sheridan C (2010) Designing Decision Support in a Evolving Sociotechnical Enterprise. Cognition, Technology \& Work, 12: 13-30. 